\title{
Distal hereditary motor neuropathy, Jerash type
}

INSERM

\section{Source}

INSERM. (1999). Orphanet: an online rare disease and orphan drug data base. Distal hereditary motor neuropathy, Jerash type. ORPHA:139552

A rare, genetic, neuromuscular disease characterized by progressive, symmetrical, moderate to severe, distal muscle weakness and atrophy, without sensory involvement, first affecting the lower limbs (towards the end of the first decade) and then involving (within two years) the upper extremities. Patients typically develop foot drop, pes varus, hammer toes and claw hands. Pyramidal tract signs (such as brisk knee reflexes and positive Babinski sign) with absent ankle reflexes are initially associated but regress as disease stabilizes ( $\sim 10$ years after onset). 